\title{
ZURBARÁN DESPUÉS DE SU IV CENTENARIO (NUEVOS DOCUMENTOS, OBRAS NUEVAS)
}

\author{
POR \\ ODILE DELENDA \\ Instituto Wildenstein de París
}

\begin{abstract}
Several events, conferences and exhibitions regarding the fourth centenary of the death of Zurbarán (1598-1998) have taken place between 1997 and 1999. Thanks to these events some unpublished documents concerning the family and artistic formation of Zurbarán have been revealed. This new documentation expands our knowledge on the painter from Extremadura. There are new paintings reappeared too. Between them an important one representing an Apparition of the Virgin to Saint Pedro Nolasco coming from the lost series of the Merced Calzada of Seville since the French invasion.
\end{abstract}

E1 7 de noviembre de 1598 Francisco de Zurbarán fue bautizado en Fuente de Cantos, pequeña ciudad extremeña que dependía juridicamente en aquellos tiempos de Sevilla ${ }^{1}$, en donde desarrollará su brillante carrera de pintor monástico. Se ha celebrado en España el IV centenario de su nacimiento mediante numerosísimas manifestaciones, cuya cumbre ha sido la importante exposición del Museo de Bellas Artes de Sevilla ${ }^{2}$ situado en el antiguo convento de la Merced Calzada, para el cual Zurbarán realizó numerosas obras.

\section{NUEVOS DOCUMENTOS}

Durante más de un año, en distintas ciudades españolas, han tenido lugar numerosos cursos, conferencias, mesas redondas y coloquios internacionales, completando así las informaciones facilitadas por las exposiciones anteriores a la de Sevilla. En julio de 1997 el Seminario de Historia del Arte de la Universidad de Valladolid Zurbarán ante su centenario (1598-1998), dirigido por el Profesor Alfonso E. Pérez Sánchez, inauguraba, en el marco de la Fundación Duques de Soria, la serie de manifestaciones dedicadas al pintor. Varios especialistas presentaron sus comunicaciones concretando lo que hasta entonces se conocía del pintor de Fuente de Cantos. En la conclusión de mi ponencia dedicada a la biografía de Zurbarán y enriquecida por

\footnotetext{
1 Antonio Martínez Ripoll, «El viaje a Madrid y el Salón de los Reinos», Ciclo de Mesas Redondas Zurbarán en su Centenario, Museo de Bellas Artes de Valencia, 24 de septiembre de 1998.

${ }^{2}$ Zurbarán IV Centenario, Sevilla, Museo de Bellas Artes, 8 de octubre-9 de diciembre de 1998.
} 
los nuevos documentos reaparecidos desde las exposiciones de 1987-1988 ${ }^{3}$ yo misma confiaba: «queda mucho por descubrir y espero que este próximo 'año Zurbarán' dé oportunidades para nuevos hallazgos ${ }^{4} \gg$. Bien parece que las conmemoraciones de dicho centenario han cumplido este objetivo. Varias publicaciones, tanto en España como en Francia ${ }^{5}$ expusieron varias novedades que han servido para enriquecer la biografía del pintor extremeño. Recordemos aquí las aportaciones más significativas.

En Fuente de Cantos, José Lamilla Prímola halló varios documentos inéditos referentes a la familia del pintor ${ }^{6}$ y sobre todo, a su hermano mayor Andrés, apellidado Guerra en los archivos, sin que realmente se sepa el origen de tal apellido. Merced a ello, hemos podido descubrir la existencia de un tal Sebastián de Zurbarán, hijo de Andrés, bautizado el día 30 de enero de 1613 en la iglesia de Fuente de Cantos y que profesa en la orden de la Merced de Sevilla el 30 de junio de 1630: «Fr. Sebastianus de Zurbarán villa de Fuente de Cantos facio profesion $\&^{a}$ et tibi $R^{d o}$ fr. Joanni de Herrera Com. ${ }^{x i}$ vice $R^{m i}$. Zebrían $\&^{a}$ anno Dñi 1630 - dic $20-J_{u n i i^{7}}{ }$. Recordemos que Fray Juan de Herrera, comendador de la Casa Grande de la Merced de Sevilla, habia firmado el 29 de agosto de 1628 un contrato muy importante con Zurbarán, del cual hablaremos más adelante ${ }^{8}$.

Un documento capital hallado por Luis Garraín Villa, el incansable archivista de Llerena, nos ha revelado otros vínculos de Zurbarán con esta misma orden religiosa, y sobre todo una cara desconocida de sus años de juventud. Por contrato firmado en 10 de abril de 1624 con Fray Francisco de Baños, comendador del convento de Nuestra Señora de la Merçed de la villa de Azuaga, el pintor se compromete a ejecutar la escultura de un Cristo en la Cruz ${ }^{9}$. Otros detalles han venido enriqueciendo la biografía del pintor durante los años vividos en Llerena ${ }^{10}$.

Por último, el R.P. Luis Vázquez, o. de m., encontró hace poco el original de la Memoria de la Pintura y Escultura de Este Real Convento, Casa Grande de la Orden de Nuestra Señora de la Merced, Redención de Cautivos, de la ciudad de Sevilla" ${ }^{11}$, importante inventario de 1730 hasta ahora solamente conocido por unas copias de la Biblioteca Colombina de Sevilla publicadas en 1922 por Sánchez Cantón ${ }^{12}$. Algunos elementos del manuscrito original no figuraban, sin embargo, en estas copias. Así, por ejemplo, descubrimos la existencia de otro cuadro de Zurbarán para el convento: «Se puso en dicha Capilla de las Reliquias, un cuadro de Nuestra Señora de la Merced con su Hijo Santísimo y coronado de rosas, es de Zurbarán». Por desgra-

${ }^{3}$ Zurbarán, New York, Metropolitan Museum, 16 septiembre-14 diciembre 1987; París, Galeries nationales du Grand Palais, 14 enero-11 abril 1988 ; Madrid, Museo del Prado, 3 mayo-30 julio 1988.

${ }^{4}$ Odile Delenda, «Biografía ilustrada de Francisco de Zurbarán. Nuevos datos», Zurbarán ante su centenario (15981998), (21-25 de julio de 1997), Universidad de Valladolid, Fundación Duques de Soria, 1999, p. 99.

${ }^{5}$ Número especial «Zurbarán», Gazette des Beaux-Arts, octubre 1998. Las novedades documentales se encuentran resumidas en la introducción al catálogo de la exposición de Sevilla (Odile Delenda, «Precisiones sobre la vida y obra de Francisco de Zurbarán», p. 13-25, traducción francesa en « Zurbarán IV centenaire», Dossier de l'art, nº 53, diciembre de 1998).

"José Lamilla Prímola, «La familia de Zurbarán (algunos datos históricos) », libro colectivo Francisco de Zurbarán (1598-1664). Su tiempo, su obra, su tierra, bajo dirección de Felipe Lorenzana de la Puente, Fuente de Cantos, 1998, p. 393-399.

7 Fragmentos de Andalucía, $\mathrm{n}^{\circ}$ 355. Esta información tan interesante nos ha sido facilitada por el padre Luis Vázquez, o. de m., del convento madrileño de la orden de la Merced, a quién se lo agradecemos de todo corazón.

8 Ver infra nota 34.

${ }^{9}$ Odile Delenda y Luis Garraín Villa, «Zurbarán sculpteur : aspects inédits de sa carrière et de sa biographie», Gazette des Beaux-Arts, marzo de 1998, p. 125-138.

${ }^{10}$ Luis Garraín Villa : «Nuevas aportaciones documentales a la biografía de Francisco de Zurbarán», en libro colectivo, ver nota 6 .

"R.P. Luis Vázquez, o. de m., «Pintura y escultura del Convento Grande de la Merced de Sevilla», Estudios, ${ }^{\text {"s }}$ 200201, enero-julio 1998, p. 191-208.

${ }^{12}$ Francisco Javier Sánchez Cantón, «La vida de San Pedro Nolasco: Pinturas del claustro del refectorio de la Merced Calzada de Sevilla», La Merced, 14 de enero de 1922, V, n ${ }^{\circ}$ 42, p. 209-216. 


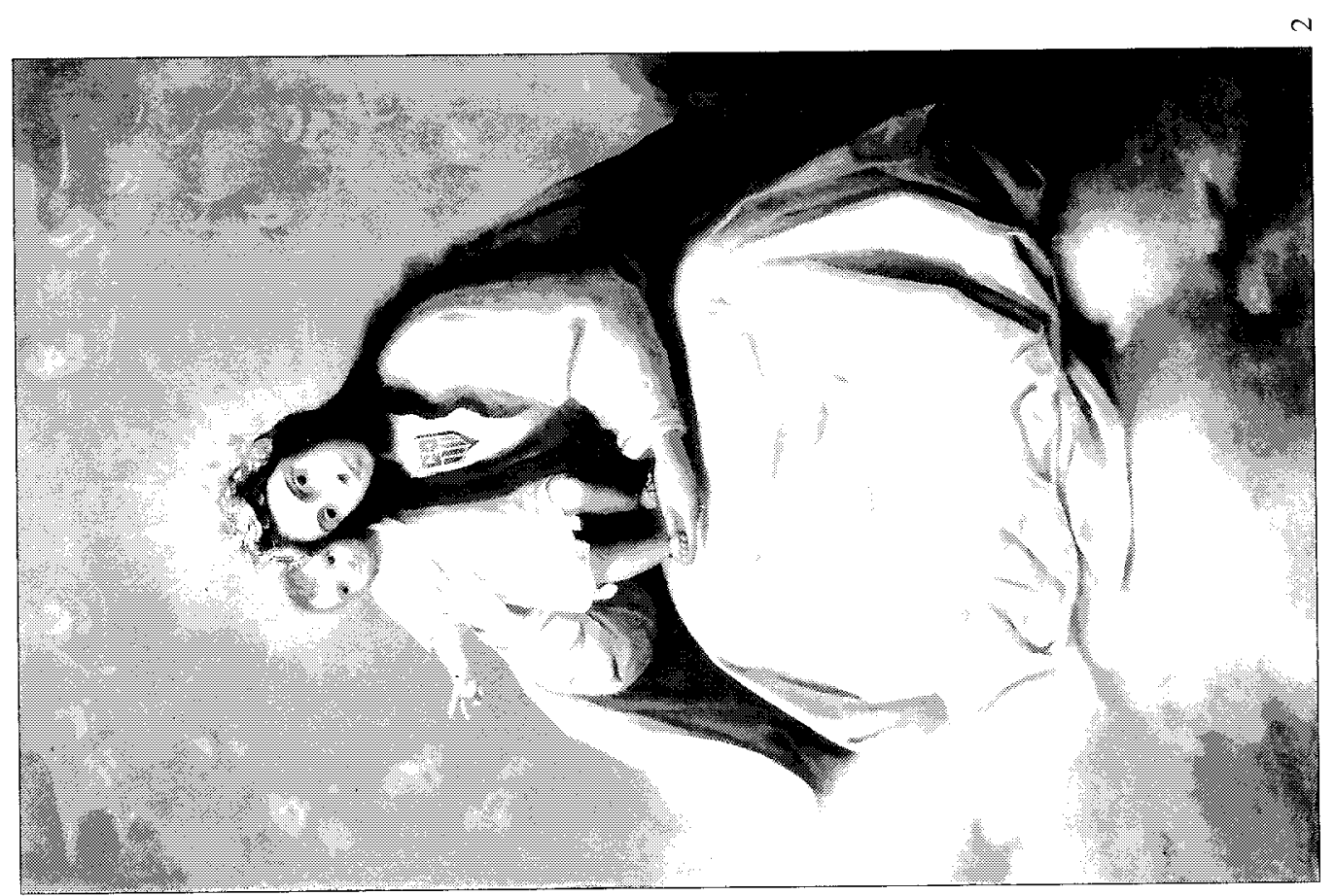

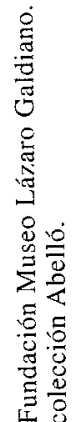

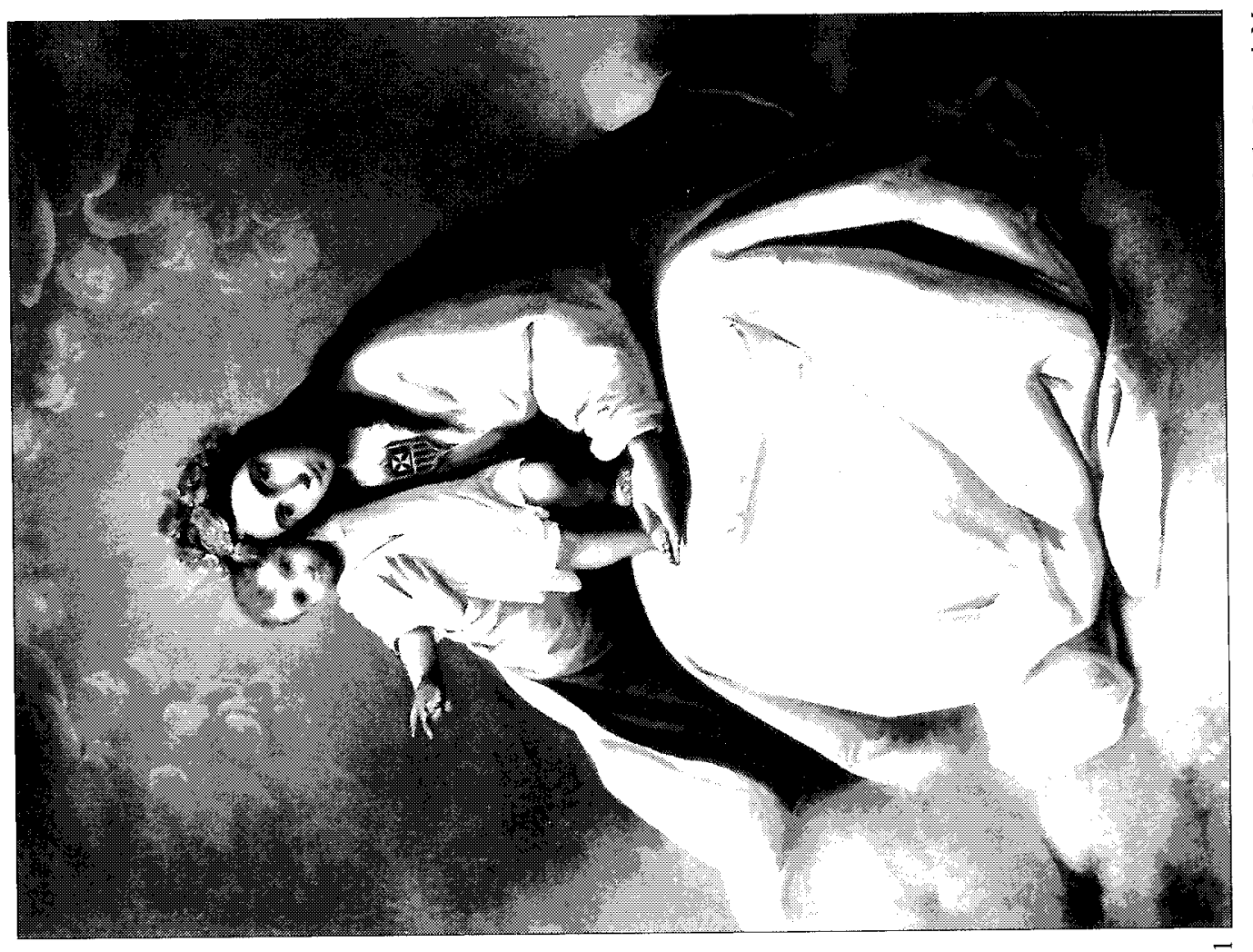

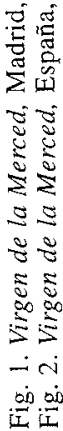


cia ninguna de las distintas versiones conocidas de la Virgen de la Merced nos parecen originales del pintor extremeño. La pequeña versión de la Fundación Lázaro Galdiano de Madrid $(100 \times 78 \mathrm{~cm})$ [Fig. 1], aunque estuvo en la Galeria Louis-Philippe (1838-1848), resulta un poco floja. También es versión del obrador la replica mayor de este cuadro que estuvo en la madrileña galeria de Helena Mola y que pertenece ahora a la colección Abelló ${ }^{13}$ (Fig. 2). Estos dos cuadros han sido recientemente restaurados y se han retirado los repintes que molestaban su visión. No sería imposible que uno de los dos, quizás la versión Abelló, fuera el cuadro de la Casa Grande de la Merced sevillana.

Al terminar con este breve compendio de los documentos hallados en este año del IV centenario, llama la atención el que la mayoria de ellos hagan referencia a los lazos entre Zurbarán y la orden de la Merced. Tan estrechos vínculos explican, sin duda alguna, la firma en 1628 del considerable contrato con la Casa Grande de la Merced Calzada. Por otra parte, las relaciones entre el pintor y la nobleza de su provincia natal aclaran, seguramente, el porqué de los importantes encargos sevillanos iniciados desde 1626. Dichas relaciones no han sido aún objeto de un estudio detenido. Así, por más que sepamos, nadie ha subrayado el hecho que, desde 1626 hasta 1629, fecha del establecimiento definitivo de Zurbarán en Sevilla, el Asistente de la capital andaluza, pertenecía precisamente a uno de los más nobles linajes de Llerena. Omnipotente representante del poder real, don Lorenzo de Cárdenas (Valladolid, 1576-Madrid, 1637), IX conde de la Puebla del Maestre, de ilustre familia extremeña, presidía el Consejo Municipal sevillano. Tan eminente personaje, capitán general de Sevilla, mayordomo del rey don Felipe IV y presidente de la Casa de Contratación de Indias, era también miembro de los Consejos de Guerra y de Estado e íntimo amigo del conde-duque de Olivares. Don Lorenzo de Cárdenas pudiera perfectamente haber sido el introductor de su joven compatriota en Sevilla. Sabemos también que su hijo, don Diego de Cárdenas, $\mathrm{X}$ conde de la Puebla del Maestre, maestre de Campo General en Sevilla y de las Milicias de Extremadura, Asistente de Sevilla entre 1648 y 1650 , fue un cliente habitual de Zurbarán ${ }^{14}$ (Figs. 3 y 6 ).

\section{CUADROS NUEVOS}

Varias exposiciones, de importancia desigual, han celebrado este IV centenario en España. En primer lugar, Zurbarán (1598-1998), modesta reunión de veintiseis lienzos, presentaba desde octubre de 1997 hasta enero de 1998, primero en Córdoba y luego en Marchena y Cádiz, obras restauradas gracias al mecenazgo de Caja Sur. En Barcelona, en abril y mayo de 1998, Maria Margarita Cuyás organizó una exposición temática en torno a las pinturas propiedad del museo, titulada Zurbarán al Museu d'Art de Catalunya, dando a conocer al público cuadros que, en algunos casos, se enseñaban por primera vez. Entre estos cabe citar una conmovedora Crucifixión con San Juan, la Virgen y la Magdalena, gran lienzo descubierto por José Milicua, firmado y fechado en 1655 , totalmente inédito y procedente de una colección americana (Fig. 4). Un conjunto de unos cuantos bodegones de Francisco y de Juan de Zurbarán permitía, asimismo, apreciar, en este campo, las excepcionales cualidades tanto del padre como del hijo, fallecido en 1649 a los 29 años de edad. Otra iniciativa interesante fue la que nos brindó

\footnotetext{
13 Virgen de la Merced, lienzo, 170 x $90 \mathrm{~cm}$. Publicada en la revista Goya, 1975, no 127, s.p. Agradecemos al Señor Abelló y a José Antonio de Urbina habernos permitido examinar el cuadro antes y después de su restauración.

${ }^{14}$ En 3 de diciembre de 1648, Zurbarán firma un recibo por 1152 reales a cuenta de «cuadros que le he vendido y entregado en todos los tiempos pasados» al conde de la Puebla del Maestre. Documento descubierto por Celestino López Martínez, citado por Paul Guinard et que yo publiqué en 1994 (Caturla-Delenda, 1994, documento n 153). Agradezco de todo corazón a Luis Garraín Villa su ayuda en esta investigación.
} 

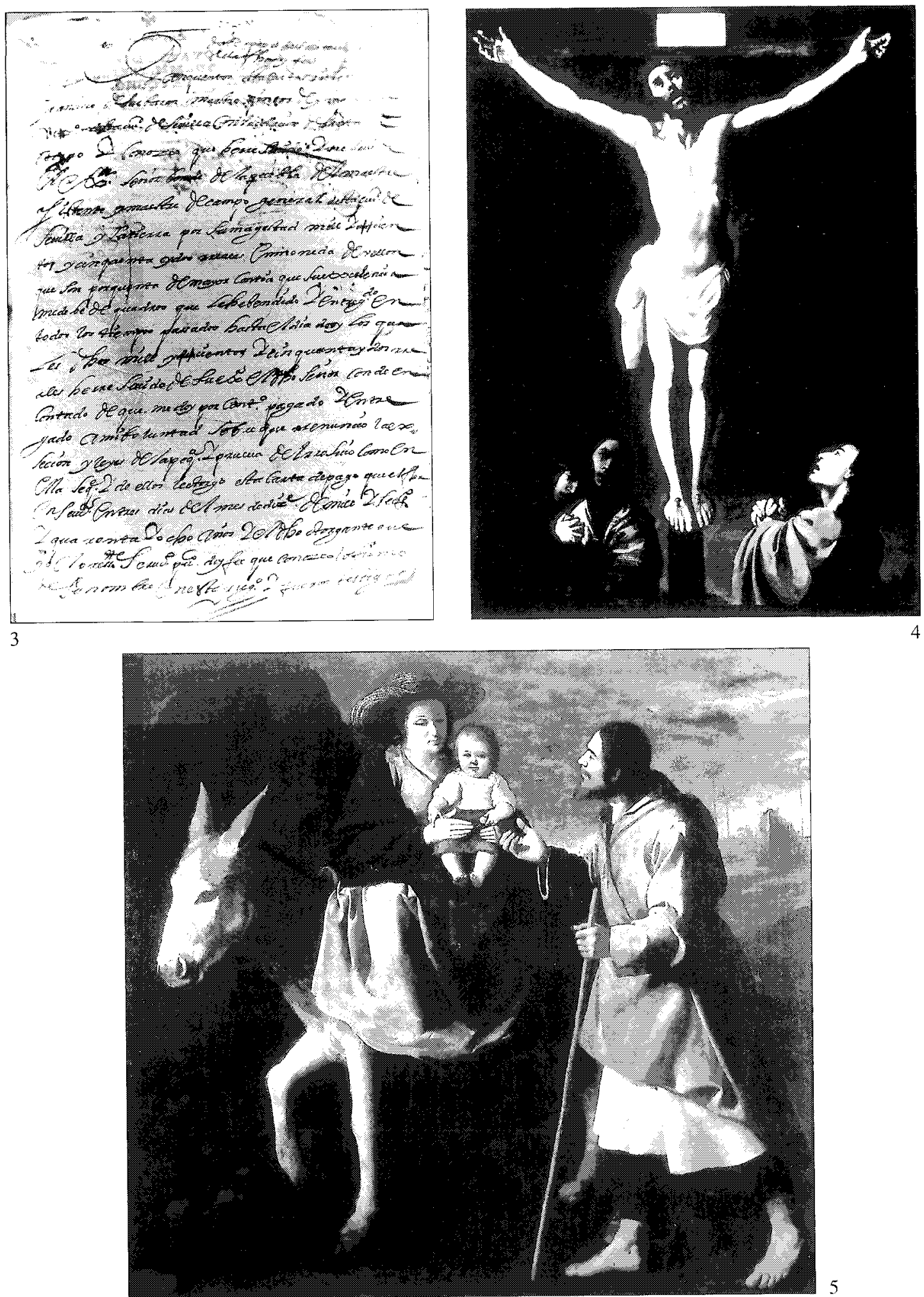

Fig. 3. Documento del 3 de diciembre de 1648, Sevilla, A.H.P., (Protocolos notariales, oficio 16, Libro 3 de 1648 , folio 563) Fig. 4. Crucifixión con San Juan, la Virgen y la Magdalena, U.S.A., colección privada. Fig. 5. Huida a Egipto, Paris, colección privada. 


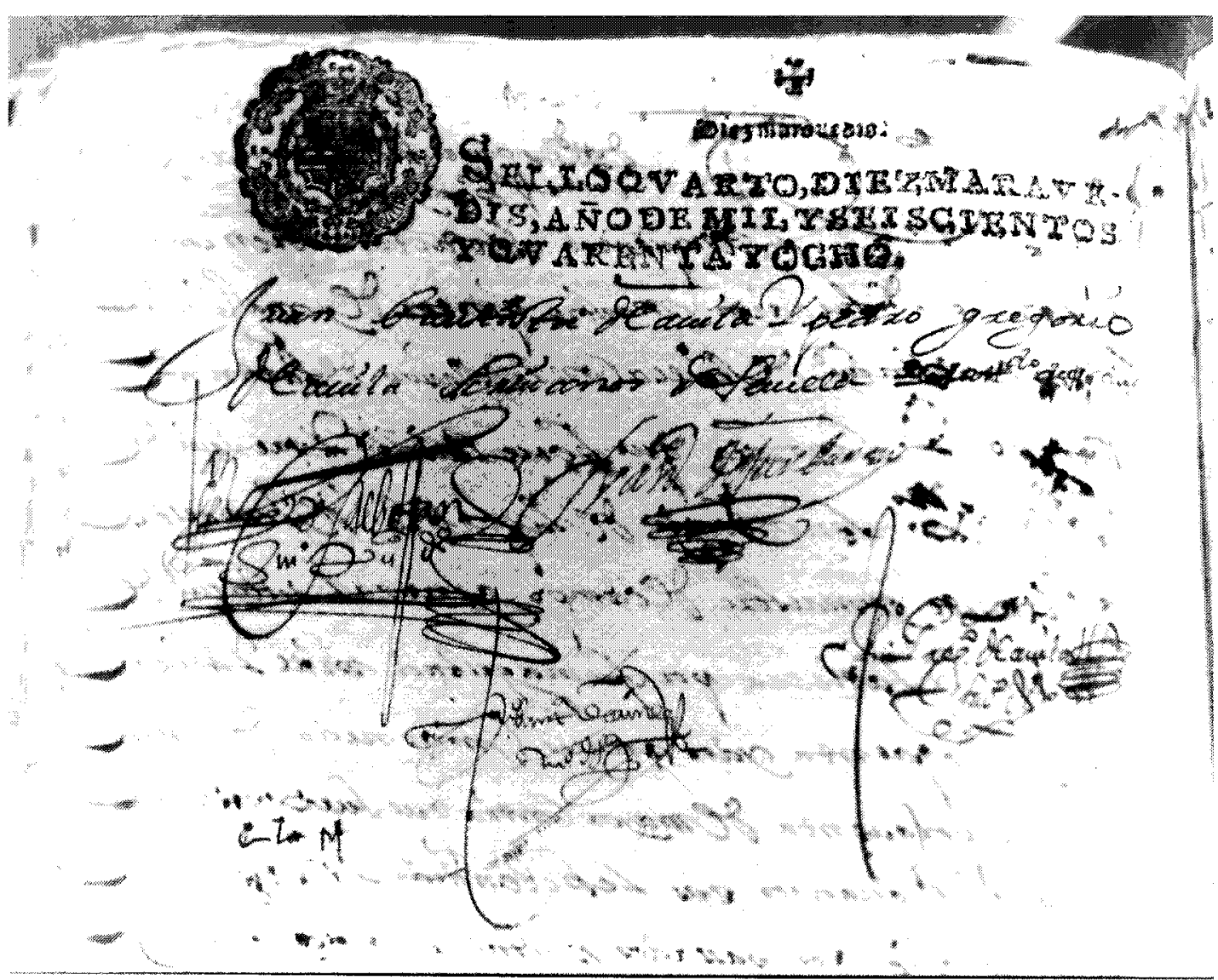

Fig. 6. Documento de Zurbarán

Benito Navarrete, que en una exposición ambulante, Zurbarán y su Obrador, Pinturas para el Nuevo Mundo, reunió treinta y ocho lienzos, de los cuales varios inéditos, presentados el verano de 1998 en Valencia, en 1999 en Madrid y México D.F., y por fin en Nueva York. Esta muestra sirvió para comprobar, en torno al magnífico San Jerónimo del Museo de San Diego (Estados-Unidos), las desigualdades del obrador del maestro en relación con la producción de series destinadas a las colonias americanas. Por fin Enrique Pareja presentó en Granada unos treinta cuadros de Zurbarán y de su obrador en abril y mayo de 1999.

El acontecimiento más destacado fue la gran exposición monográfica organizada en el Museo de Bellas Artes de Sevilla por Enrique Valdivieso (Zurbarán. IV Centenario, octubre diciembre 1998), reuniendo un excepcional conjunto de más de noventa cuadros de Zurbarán. El museo, antiguo convento de la Merced Calzada restaurado y acondicionado con motivo de la Exposición universal de 1992, resultó ser el marco ideal para tan importante acontecimiento, siendo el primero dedicado en la capital andaluza al artista cuya carrera artística se desarrolló principalmente en dicha ciudad.

Con tal motivo, varios cuadros inéditos descubiertos por los especialistas de Zurbarán han sido confrontados con las obras confirmadas del pintor. Recordaremos brevemente los hermosos hallazgos de nuestros colegas españoles antes de comentar cuatro cuadros procedentes de colecciónes privadas y cuyos dueños nos han otorgado generoso permiso de publicar aquí.

Ante todo, es menester rendir homenaje a nuestro malogrado amigo, Juan Miguel Serrera, experto en el arte de Zurbarán, fallecido antes de tiempo. En el número especial de la Gazette 
des Beaux-Arts ${ }^{15}$, presentó un interesante San Francisco de Paula firmado y fechado en 1659 , que figuraba en la exposición de Sevilla $\left(\mathrm{n}^{\circ}{ }^{84}\right)$ al lado de su probable pareja, el San Francisco rezando de la colección Arango ( ${ }^{\circ} 83$ ).

Asimismo, en dicha exposición, figuraban dos cuadros dados a conocer por Benito Navarrete: San Francisco en extásis del Museo Soumaya de México D.F. $\left(\mathrm{n}^{0} 52\right)^{16}$, réplica un poco dura de medio cuerpo con paisaje en el fondo del célebre San Francisco de la National Gallery de Londres, y San Pedro orando de la colección Juan Zavala Fernández-Valdés (n $\left.{ }^{\circ} 68\right)^{17}$. Esta última obra se presentó al lado del San Pedro orando ante Cristo atado a la columina del Palacio Arzobispal de Sevilla ( ${ }^{\circ} 67$ ), identificado en 1985 por Enrique Valdivieso, comisario de la exposición. Tan hermosos originales, ejecutados sin duda con varios años de distancia, demuestran la existencia de versiones autógrafas de un mismo tema. El precioso descubrimiento por Valdivieso de una Santa Familia $\left(\mathrm{n}^{\circ} 91\right)^{18}$ en una colección privada, completaba una serie de Virgenes con el Niño tardías, acompañadas a menudo de un modesto bodegón admirablemente pintado; prueba fehaciente de que si el anciano maestro cambió su manera, todas sus cualidades de ejecución permanecieron hasta el final de su carrera ${ }^{19}$.

Desgraciadamente, la gran Alegoría de la Caridad adquirida por el Prado en 1997 no ha participado en ninguna de las distintas exposiciones de este excepcional año del IV centenario. Esta obra sin duda tardía y de tema interesante, se merecía un cotejo con los lienzos de la misma época ${ }^{20}$.

\section{La Huida a Egipto}

Entre las obras que yo misma pude identificar cabe señalar una hermosa Huida a Egipto (Fig. 5), fechada aproximadamente a finales del decenio prodigioso 1630-1640, que fue presentada en Sevilla ${ }^{21}$ con gran éxito. En 1659, Jerónimo de Tordera, cuñado de Zurbarán encargado de velar por sus asuntos en Sevilla durante la residencia de los esposos en Madrid, tenía unas cuantas pinturas para servir de fianza en el caso de que no pudieran saldar algunas de sus deudas. En una lista de veinte cuadros, figuraban dos Huidas a Egipto ${ }^{22}$. Sin embargo no se conocía ninguna obra con tal tema, hasta que en 1954 Diego Angulo Íñiguez atribuyó a Zurbarán una bonita Huida a Egipto legada por el pintor Gigoux al Museo de Besancon; en $1894^{23}$. Posteriormente la crítica no ha confirmado del todo tal atribución: unas cuantas torpezas en el trazado, el diminuto tamaño de las figuras y la ausencia de volúmen de estas últimas, corres-

\footnotetext{
15 Juan Miguel Serrera $\uparrow$, «Ultima étapa de Zurbarán en Madrid: contribuciones y reflexiones», Gazette des Beaux-Arts, octubre de 1998, p. 177-184, Fig. 1 a 3 y catal. exp. Sevilla, 1998, n 84.

${ }^{16}$ Benito Navarrete, catal. exp. Zurbarán y su obrador, Valencia, 1998, p. 140, fig. [23.1].

17 Benito Navarrete, «Algo más sobre Zurbarán», Goya, n²51, 1996, p. 284.

${ }^{18}$ La Virgen de este cuadro repite la de la Imposición de la casulla a San Ildefonso de Toledo, del retablo del antecoro del monasterio de Guadalupe. Lo cual plantea la fecha tardía de este retablo y de su compañero.

${ }^{19}$ Con motivo de estas exposiciones varios cuadros poco conocidos se expusieron por vez primera. Muchas obras restauradas para estas ocasiones fueron en la mayoría de los casos buenas sorpresas. El Cristo crucificado de la iglesia de la Granada de Llerena, pintado sobre tabla, restaurado en el madrileño Instituto Tekne, ha revelado bajo toscos repintes y retoques unas calidades inesperadas. Se publicará en breve con los estudios técnicos.

20 Fue presentada por Miguel Zugaza, Director del Museo de Bellas Artes de Bilbao, desde el 10 de octubre de 2000 hasta el 14 de enero de 2001 en la exposición Zurbarán, la obra final: 1650-1664 (comisario A.E. Pérez Sánchez).

21 La Huida a Egipto, lienzo, $150 \times 159 \mathrm{~cm}$, Francia, colección privada. Catálogo de la exposición de Sevilla, 1998, $\mathrm{n}^{\circ} 5 \mathrm{l}$.

${ }^{22}$ Duncan T. Kinkead, «The Last Sevillian Period of Francisco de Zurbarán», The Art Bulletin, 1983, LXV, p. 309-310,

y M. L. Caturla-O. Delenda, 1994, documentos 185 y 187

${ }^{23}$ Diego Angulo Íñiguez, «Algunos cuadros españoles en museos franceses», Archivo español de Arte, 1954, XXVII, p. 316-317.
} 

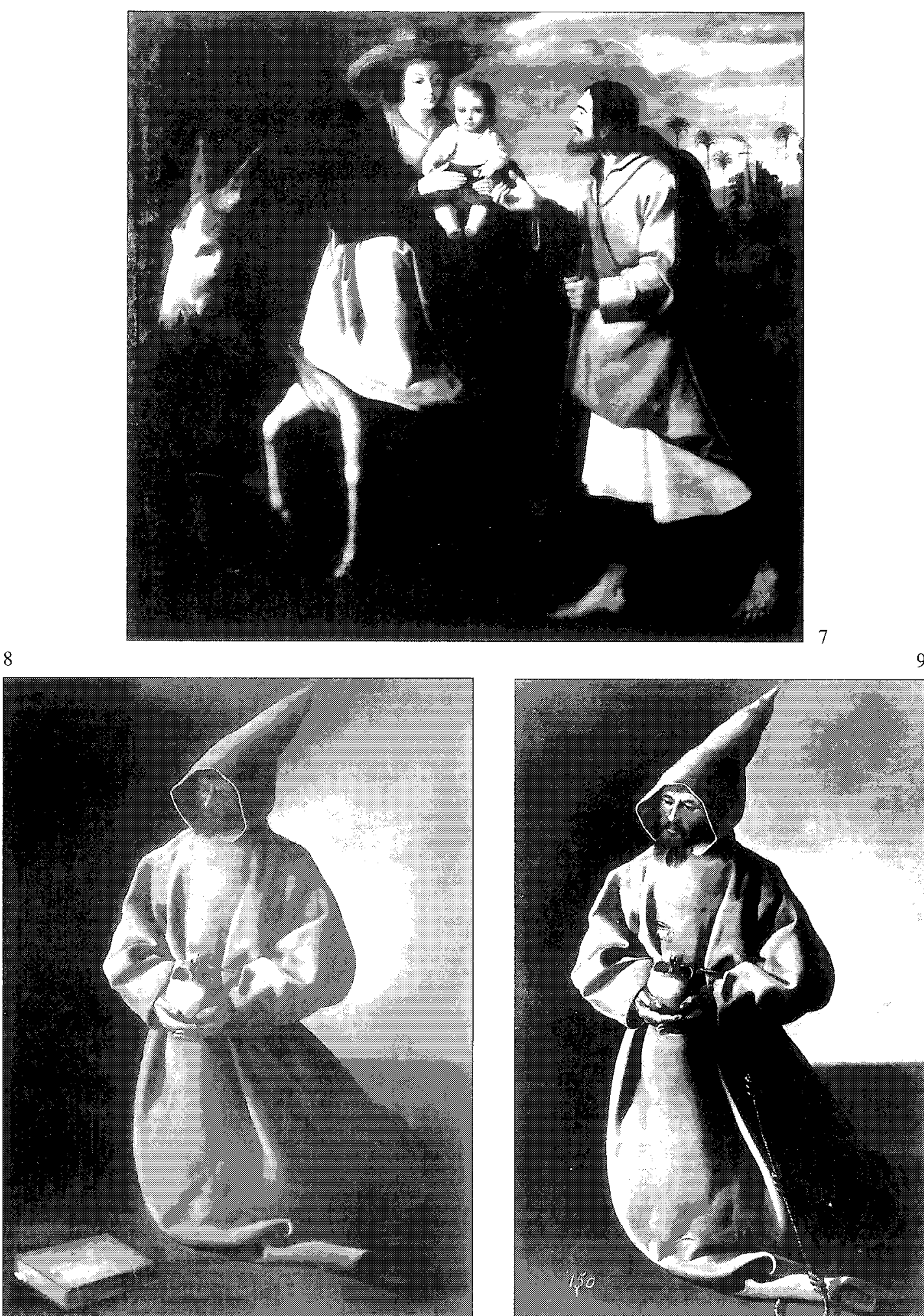

Fig. 7. Huida a Eoipto, Oxford, Ashmolean Museum

Fig. 8. San Francisco meditando con una calavera. Milano, colección privada.

Fig. 9. Id.. Zurich. colección Loschbichler. 
ponden más bien a un buen ayudante de Zurbarán, que pudo repetir con variantes un celebrado tema del maestro, probablemente el que aquí presentamos, conocido hoy día por varias copias.

Una Huida a Egipto de Zurbarán se vendió en París el 24 de mayo de $1839^{24}$, en un momento de gran actividad en el mercado del arte pictórico español a raíz de las ventas masivas en España con motivo de la Desamortización en 1835-1836. Cabe la posibilidad de que fuera nuestro cuadro del cual sólo tenemos muy pocas referencias históricas. Puede que saliera de España a finales de los años 1970 después de haber pasado en venta pública como anónimo ${ }^{25}$. Hace unos quince años se encontraba en Bélgica cuando lo compró su nuevo dueño. Actualmente se conocen varias copias de este cuadro. Una réplica de obrador de igual tamaño entró en el Ashmolean Museum de Oxford en 1955 como anónimo español (Fig. 7). Una versión algo reducida pero desgraciadamente exageradamente restaurada, fue señalada por María Luisa Caturla en la iglesia de Los Santos de Maimona, cerca de la villa de Llerena. El original pudiera haber sido pintado para el retablo de la Granada de dicha villa en el cual se debían incluir escenas mariales ${ }^{26}$. Por último, el éxito del tema está comprobado por una copia tardía, casi literal, ejecutada por el pintor peruano Joaquin Urreta, quién firma y fecha en 1767 una Huida a Egipto conservada hoy en día en el convento de los Descalzos de Lima.

Zurbarán representa la escena tal como la cuentan los Evangelios: «José se levantó, tomó al niño y a su madre de noche, y partió hacia Egipto» (Mt. 2, 13-14), siguiendo minuciosamente los consejos de Pacheco salvo en la colocación de San José: «Nuestra Señora sentada en su asnita, con su manto azul, ropa rosada y toca en su sombrero de palma puesto [...] San Josef delante, haldas en cinta, con su báculo ${ }^{27} \gg$.

San José, con manto de viaje, va caminando un poco atrás; el ademán de su mano derecha dirigido a María significa al mismo tiempo explicación e invitación: es preciso darle a la Virgen, sumisa, los motivos de tan precipitado viaje nocturno. Mientras parece que los padres dialogan silenciosamente, el Niño, de frente, dirige la mirada hacia el espectador. Todo un bebé rollizo, sujeta con su manita una manzana, evocación del pecado original que él ha venido a redimir, mientras que da la otra manita a su madre, la que intercede por nosotros. Llaman la atención esos juegos de manos admirablemente pintados. Cuando el Niño confiado se interesa por lo que le rodea, los ojos de José y María expresan una interioridad intensa, típica de Zurbarán, que de este modo, restituye de una manera tangible la atmósfera de oración y recogimiento. La ejecución monumental de las figuras, la calidad de los drapeados y lo refinado de los colores de este lienzo perfectamente restaurado, han hecho de él una de las sorpresas más gratas de la exposición de Sevilla.

\section{San Francisco meditando con una calavera}

Este San Francisco ${ }^{28}$ (Fig. 8), descubierto hace poco, sólo era conocido por una buena réplica de obrador expuesta en 1925 en la galería Charpentier ${ }^{29}$ (Fig. 9). Ligeramente mayor que el original que aquí se presenta, se puede notar en esta última réplica algunas variantes. Por

\footnotetext{
${ }^{24}$ Notice des tableaux des Écoles Italienne, Espagnole, Flamande et Française, vente du Samedi 15 Mai 1839 à Paris, Hôtel de MM. Ies Commissaires-Priseurs de la Seine « $n^{\circ} 17$ : ZURBARRAN. La fuite en Égypte».

${ }^{25}$ Le agradecemos esta información a Juan José Junquera.

26 María Luisa Caturla-Odile Delenda, 1994, p. 181.

${ }_{27}$ Arte de la Pintura, ed. Bassegoda i Hugas, 1990, p. 625.

28 San Francisco meditando con una calavera, lienzo, $114 \times 89 \mathrm{~cm}$, Milano, colección privada. Odile Delenda, «Zurbarán en la hora actual: nuevos documentos, nuevas orientaciones», Simpósio internacional Zurbarán y su época, Fuente de Cantos, Llerena y Guadalupe, 28-30 de mayo de 1998, p. 18-19 y Fig. 5.

${ }^{29}$ San Francisco meditando con una calavera, lienzo, $142 \times 93 \mathrm{~cm}$, Zurich, colección Loschbichler.
} 
ejemplo el libro ha desaparecido, se ha añadido un cíngulo y un rasgón en el hábito revelándose así el estigma de la llaga del pecho, y la barba de dos puntas está más iluminada. No obstante, debido al muy duro tratamiento de la luz, a la falta total de accesorios y a la poca estabilidad de la figura, Guinard describía el lienzo como: «probable réplica de obrador, que no deja de sobrecoger ${ }^{30}{ }_{\gg}$.

Tan acertada intuición del gran historiador está ahora comprobada por la aparición del lienzo de Milán, desgraciadamente en mal estado antes de la restauración hecha por Grassi en Nueva York pero que sin embargo, demuestra todas las calidades de un original de Zurbarán contemporáneo sin duda, del San Francisco firmado y fechado en 1632 de la colección Shaw, en Buenos Aires ${ }^{31}$.

El poverello de Asis vestido del hábito sin muceta, con la capucha puntiaguda de los capuchinos, aparece absorto en la meditación sobre las postrimerías del hombre, evocadas por la calavera que contempla sin mirarla de verdad, arrebatado en éxtasis por una visión interior. El fondo, casí negro a la izquierda, se aclara en el suelo, y sobre todo en la parte derecha violentemente iluminada. Tan brutal iluminación, típica de las obras de juventud, crea profundas sombras muy oscuras en el sayal del hábito tratado en una gama de beiges, desde un tono casí ebúrneo donde se quiebran los pliegues, hasta uno pardo oscurecido en la parte que queda a contraluz. Iguales tonos se vuelven a encontrar en el grueso libro, encuadernado de clara piel, caido a los pies del santo. El rostro magnífico, se desvanece en la sombra de la capucha y anuncia el tan conmovedor rostro del San Francisco en extásis de la National Gallery de Londres, con la intensa iluminación de lado que aclara, con blanco toque, la linea saliente de la nariz.

Descubierto en Inglaterra, este cuadro podría pertenecer a la Galería Española de LuisFelipe: una obra, con mismo tema y tamaño ligeramente inferior ${ }^{32}$, hasta hoy en paradero desconocido, correspondería al cuadro milanés.

\section{La Virgen niña dormida}

En la exposición Zurbarán de Barcelona se expuso al lado de la Virgen niña dormida de la Catedral de Jerez de la Frontera (Fig. 10) una versión del mismo tema del Banco Central Hispano publicada en 1996 por Alfonso E. Pérez Sánchez. En realidad este cuadro, algo más grande, se diferencia del jerezano en numerosos detalles. Actualmente una espesa capa de barniz recubre el lienzo y aunque la calidad de ejecución sea muy buena, la Virgencita del Banco nos parece una excelente réplica de taller de una versión inédita encontrada recientemente en una colección francesa (Fig. 11). La composición es idéntica en el cuadro francés y en el del Banco pero hay varias diferencias con la Virgen niña de Jerez: el cajón entreabierto de la mesilla está situado en otro lado, el bodegón no figura exactamente en el mismo sitio y las flores, aunque sean las mismas (rosa, clavel y azucena), se enfocan con matices distintos. La niña dormida, aparentemente sentada directamente en el suelo en la versión de Jerez, descansa sobre un cojín oscuro en los lienzos francés y madrileño. El cuadro recién aparecido resulta una versión nueva de estas otras en las cuales Zurbarán nos ofrece su más hondo y encantador sentir hogareño, personal y genuina aportación al arte español del Siglo de oro.

\footnotetext{
${ }^{30}$ Paul Guinard, Zurbarán et les peintres espagnols de la vie monastique, [1960], 1988, p. $250, \mathrm{n}^{\circ} 353$.

31 Guinard, op. cit., $\mathrm{n}^{\prime \prime} 352$.

32 Jeannine Baticle, Cristina Marinas, La Galerie espagnole de Louis-Philippe au Louvre 1838-1848, París, 1981, $\mathrm{n}^{\circ} 357$, «Saint François en prière, Haut. $1 \mathrm{~m} .08 \mathrm{c}$ - Larg. $0 \mathrm{~m} .83 \mathrm{c}$. Vente Londres, $1853, \mathrm{n}^{\circ} 52$. Acquis par Bryant pour 50 livres».
} 

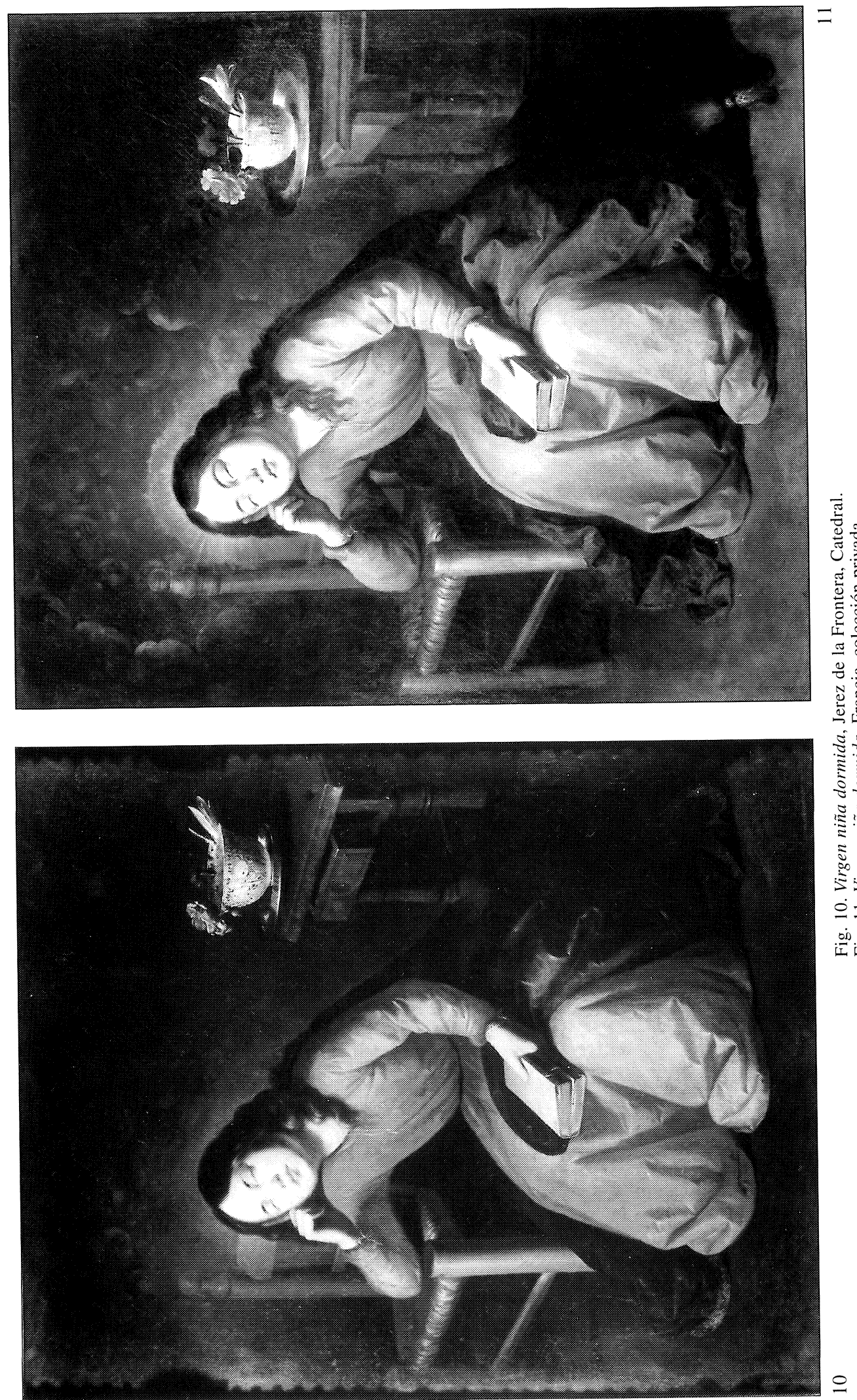


\section{Aparición de la Virgen a San Pedro Nolasco}

Entre los cuadros que hace poco han vuelto a reaparecer, nos llama especialmente la atención una Aparición de la Virgen a San Pedro Nolasco $(165 \times 204 \mathrm{~cm})$ (Fig. 13), perteneciente al ciclo de la vida del fundador de la orden de la Merced y destinado al claustro de Bojes del convento de la Merced Calzada en Sevilla. Muy a nuestro pesar, no ha sido posible conseguir el préstamo de este gran lienzo para la exposición de Sevilla, en donde se le hubiera cotejado con los cuadros de la misma serie propiedad del Prado, presentados en el marco de la antigua Casa Grande de la Merced para la cual se pintó dicho conjunto. Sin embargo una reproducción en colores de esta obra excepcional figuraba en mi introducción al catálogo de la exposición ${ }^{33}$.

Por contrato con fecha 29 de agosto de 1628 Zurbarán se había comprometido con el comendador del convento, Fray Juan de Herrera, para terminar, antes de finales de agosto de 1629: «[...] veynte e dos quadros de pintura de la ystoria de sant pedro de nolasco para bestir el segundo claustro [...] que tengan dos baras de alto y dos y media de ancho poniendo en cada uno las figuras e demas cosas quel padre comendador me ordenare sean pocas o muchas para cuyo efecto yo e las demas gentes que fuere necesario bendremos a esta ciudad por el mes de setiembre $[\ldots]^{34} \gg$. No se cumplió al pié de la letra el contrato, capital para el artista ya que le permitió dejar definitivamente Llerena para establecerse en Sevilla ${ }^{35}$. En efecto, si se entregaron a tiempo unos cuadros (Aparición de San Pedro crucificado a San Pedro Nolasco, firmado y fechado 1629, Madrid, Museo del Prado) [Fig. 15], otros sin embargo fueron realizados después del plazo fijado (La Entrega de la Virgen del Puig al rey Jaime I, firmado y fechado 1630 , The Cincinnati Art Museum, y La Rendición de Sevilla, firmado y fechado 1629, Gran Bretaña, colección The Duke of Westminster). Lo más probable es que, de las veintidos pinturas contratadas, algunas no fueran ejecutadas: en 1780, Ponz nombra sólo quince cuadros en el claustro de los Bojes, que asimismo los vio Arana de Valflora en 1789. Sin embargo en 1800, Ceán Bermúdez recuenta doce, lo mismo que Matute en la misma época. Antes de este año del IV centenario, sólo habían sido localizadas diez obras correspondientes a los criterios del encargo, el cual se dispersó antes de $1810^{36}$. Cinco de ellas son de Zurbarán: además de los lienzos ya citados, son de su mano La Visión de la Jerusalén celeste del Prado, y La Salida de San Pedro Nolasco hacia Barcelona del Museo Franz Mayer de México, realizado este último con algo de participación del obrador. Cuatro lienzos conservados en la catedral de Sevilla, probablemente de Zambrano ${ }^{37}$, corresponden a los ayudantes del maestro, mientras que el Nacimiento de San Pedro Nolasco del Museo de Bellas Artes de Burdeos, sustituiría, sin duda, al primer cuadro de Zurbarán «que hubieron de cambiar en la historia ${ }^{38}$ ».

San Pedro Nolasco (h. 1180-1249?) fundador de la orden de Nuestra Señora de la Merced para la Redención de los cautivos, fue canonizado el 30 de septiembre de 1628 «por vía de culto inmemorial», durante el pontificado del papa Urbano VIII, tras setenta días de un proceso cuya instrucción habría durado dos años. En Sevilla los festejos en honor a la canonización

\footnotetext{
${ }^{33}$ Odile Delenda, «Precisiones sobre la vida y obra de Francisco de Zurbarán», catal. exp. Zurbarán IV Centenario, Sevilla, 8 de octubre-9 de diciembre de 1998, p. 17, Fig. 3.

${ }^{34}$ Celestino López Martínez, Desde Martínez Montañés hasta Pedro Roldán, Sevilla, 1932, p. $221-222$.

${ }^{35}$ Claudie Ressort y Juan Miguel Serrera han hecho el balance sobre las obras de Zurbarán para la Merced Calzada en el catálogo de la exposición Zurbarán, Madrid, 1988, p. 137-149. Ver también el estudio detallado de José Fernández López, «Las pinturas del claustro de los Bojes», Programas iconográficos de la pintura barroca sevillana del siglo xvII, Sevilla, 1991, p. $186-199$

${ }^{36}$ En una carta fechada en 3 de febrero de 1810. Fréderic Quillet advierte que «La Merced lo ha vendido todo, menos tres Murillos» (Marqués de Saltillo, Mr. Fréderic Quillet comisario de Bellas Artes del Gobierno Intruso [1809-1814], Madrid, 1933, p. 16-18).

${ }^{37}$ Enrique Valdivieso, Historia de la pintura sevillana, 1987, p. 189.

${ }_{38}$ Memoria de 1730 , Vázquez, op. cit., p. 199.
} 

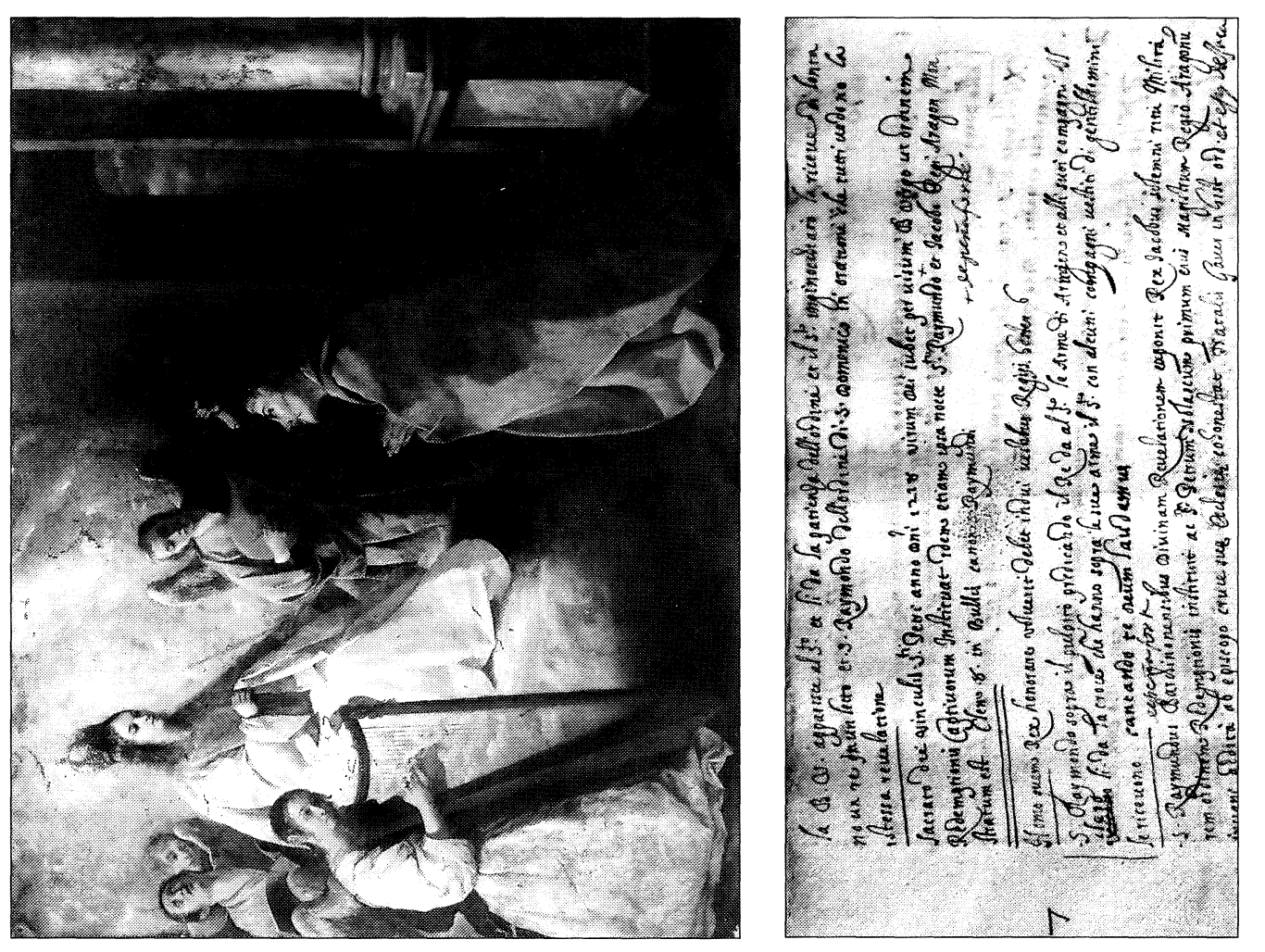

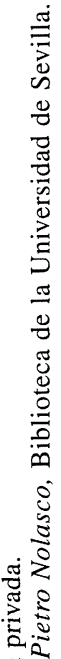

$\stackrel{m}{2}$

У

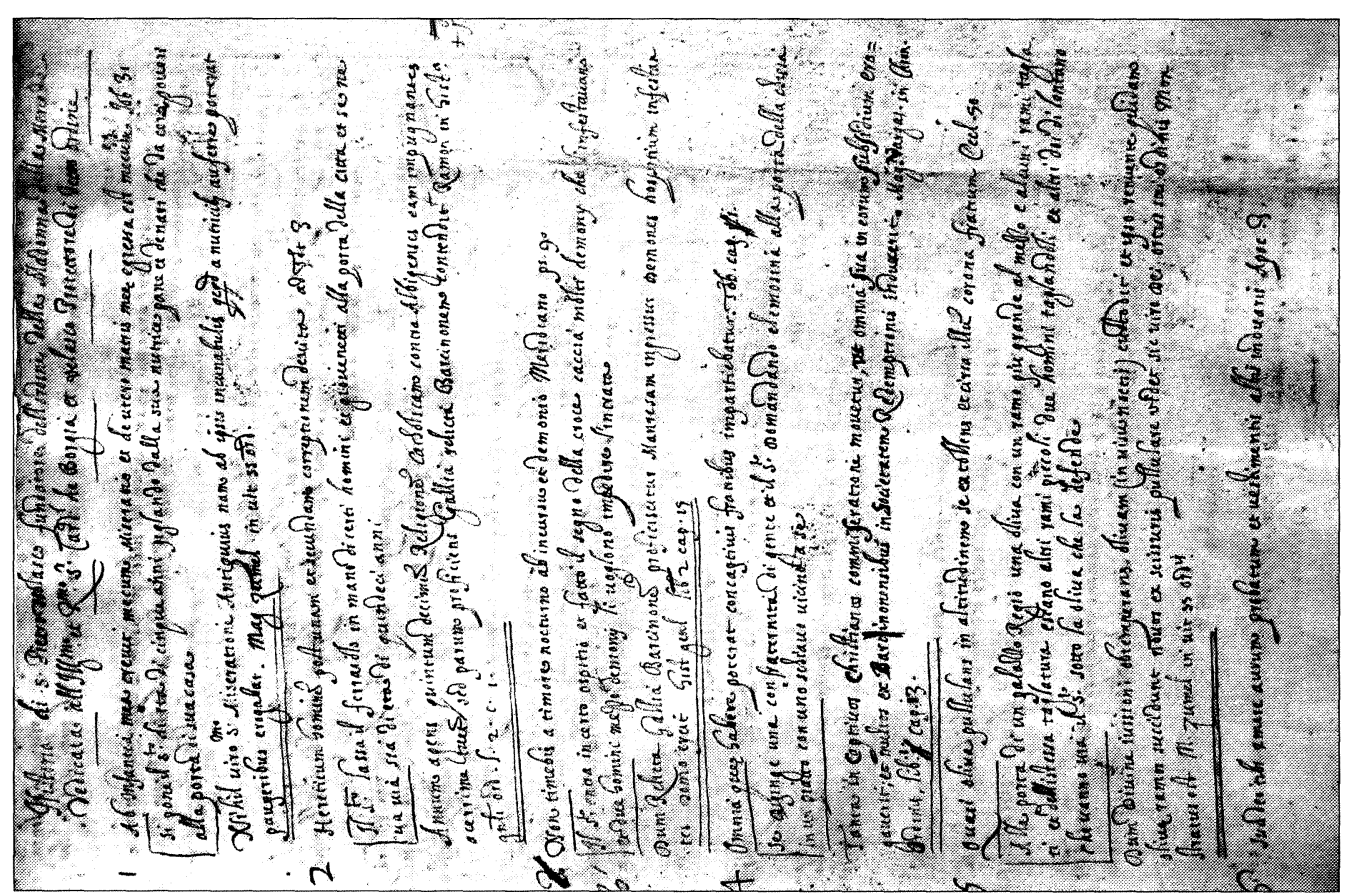

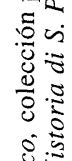

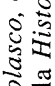

迹

น. 
se celebraron con brillantez en mayo de $1629^{39}$. Suponemos que por dichas fechas ya estaban colocados algunos de los cuadros de Zurbarán en el convento de los Mercedarios.

Se conserva en la biblioteca de la Universidad de Sevilla una compilación de los documentos reunidos para la causa de canonización, en forma de nueve cuadernillos manuscritos y cosidos. De capital importancia ha resultado el octavo cuadernillo en lo que se refiere a la iconografía del santo fundador, que casí no se había representado antes de su canonización. Dicho manuscrito describe en efecto una Vida de San Pedro Nolasco en estampas, compuesta de veinticinco grabados, aunque en la actualidad las ilustraciones ya no van juntas con el texto redactado en latín y en español ${ }^{40}$. Siete de ellas han aparecido en la Biblioteca Nacional de Madrid. En manos particulares están cuatro estampas, algo más pequeñas, al parecer calcadas sobre la primera serie, con leyendas enteramente en castellano. Los dibujos para ese conjunto, los proporcionó entre 1622 y 1623 el pintor aragonés Jusepe Martínez que, a la sazón, residía en Roma, y varios artistas ejecutaron los grabados en 1627 (Johan Fiedrich Greuter, Matthaus Greuter padre y Lucas Ciamberlano). En sus investigaciones sobre la estancia en Roma de Jusepe Martínez, María Elena Manrique no logró encontrar al opúsculo original de la Vida de San Pedro Nolasco, que sin embargo, se volvió a publicar a mediados del siglo xvirI. Los grabados de la Biblioteca Nacional de Madrid pertenecen a esta segunda tirada ${ }^{41}$.

Fray Juan de Herrera, que velaba por el cumplimiento del encargo, proporcionaría a Zurbarán la serie de grabados para realizar algunas de las pinturas encargadas, aún sin antecedentes iconográficos ${ }^{42}$. En el cuadernillo conservado en la Universidad de Sevilla, cada grabado, descrito en castellano, va acompañado por dos inscripciones latinas que, asimismo, figuran en las estampas encontradas. La primera, escrita en mayúsculas en una tarjeta arriba de la estampa, es una corta sentencia tomada de las sagradas escrituras y relativa al tema. La otra, en minúsculas, forma la leyenda de cada escena, indicando la fuente literaria de tal escena con el título «S. Petrus Nolasco FUnd.».

Por desgracia, no se ha encontrado la estampa del no 6 (Figs. 12 y 14). Lleva la frase latina «svadeo tibi emere a me avrvm probatvm et vestimentis albis indvaris» (Ap. 3, [18]). Cita truncada del versículo del Apocalipsis: «Te aconsejo que me compres oro acrisolado en el fuego, vestidos blancos con que cubrir la vergüenza de tu desnudez» y obvia alusión al hábito blanco de la Merced que María, apareciendo en una nube luminosa y dorada, entrega al joven santo arrodillado en el cuadro de Zurbarán. La escena, descrita en italiano, corresponde también, en parte, a la estructura del lienzo: «La B.[eata] V.[ergine] apparisce al $S^{\text {to }}$ et li da la patienza dell'ordine et il $S^{\prime \prime \prime}$ inginocchato la riceve di lontano un re in un letto et $S$. Raymondo dell'ordine di S. Domenico in oratione che tutti vedino la istessa revelatione. [La Sma. Virgen aparece al Santo y le da el hábito de la Orden y el Santo la recibe de rodillas. A lo lejos, un Rey en el lecho. En otro plano, S. Raimundo de la orden de S. Domenico en oración. Todos reciben la misma revelación.]». El comentario, en latín, especifica la fecha de la aparición: $1^{\circ}$ de agosto de 1218, el momento: la noche y la fuente escrituraria: la bula de canonización de San Raimundo [de Peñafort]. De hecho el episodio de la triple aparición (al joven Pedro No-

39 Desde el domingo 27 de mayo hasta el domingo 3 de junio, según documentos señalados por Francisco Morales Padrón, Memorias de Sevilla, Córdoba, 1981, p. 63. Desde el día 21 hasta el día 30 de abril de 1629 en presencia del rey D. Felipe IV y de la Corte, según Fr. Alonso Remón, Las Fiestas solemnes y grandiosas [...] a S. Pedro Nolasco, Madrid, 1629.

40 J. P. Delgado Varela. «Sobre la canonización de San Pedro Nolasco», Estudios, enero-abril de 1956, n" 34, p. $265-295$.

\$ María Elena Manrique Ala, «usepe Martínez, un ilustrador del siglo xvi. Estudio de sus estampas romanas para una Vida de San Pedro Nolasco», Artigrama, núm. 12, 1996-1997, «Resúmenes de memorias de Licenciatura», p. 711-713. Agradecemos al R. P. Saúl Perelo Meza, o. de m.. que nos ha puesto en relaciones con esta joven investigadora.

${ }^{2}$ Santiago Sebastián, "Zurbarán se inspiró en los grabados del aragonés Jusepe Martínez», Goya, n”128, 1975, p. $82-84$. 


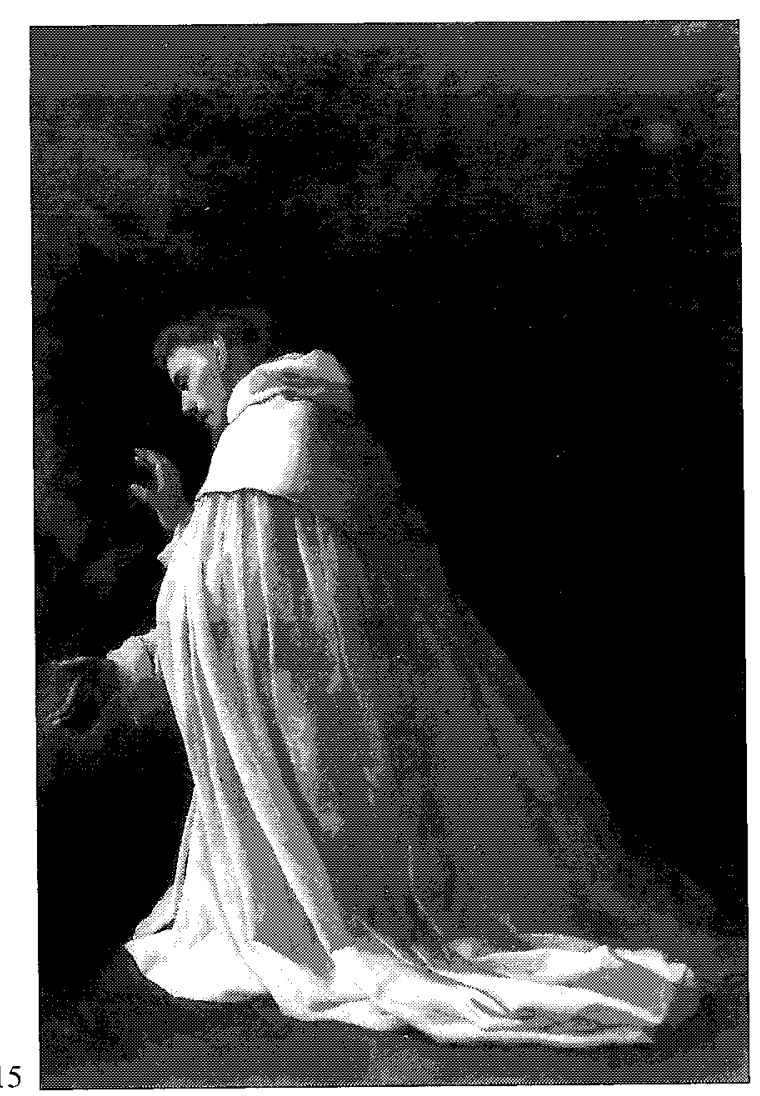

15

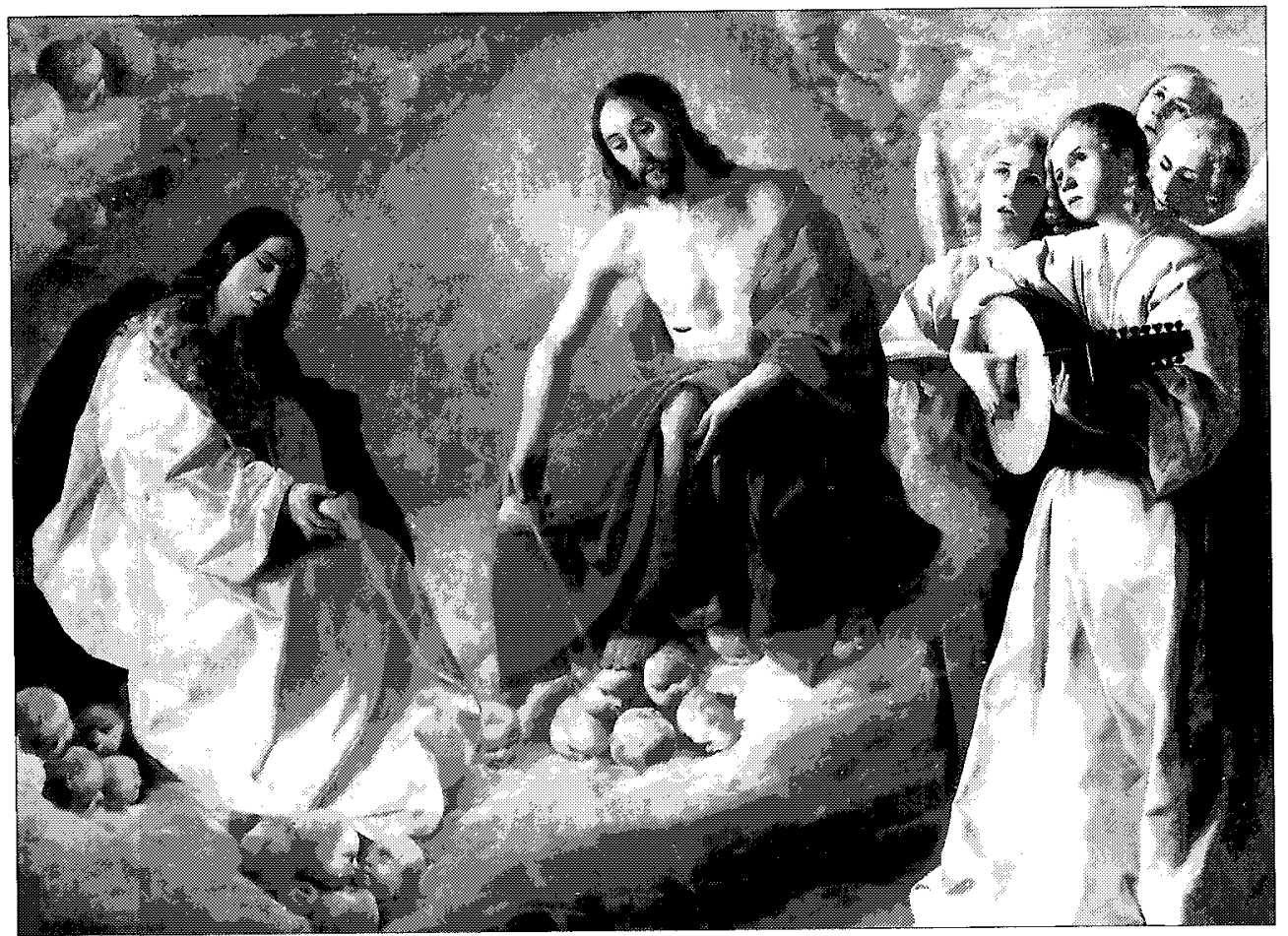

Fig. 15. Aparición de San Pedro crucificado a San Pedro Nolasco (detalle), Madrid, Museo del Prado. Fig. 16. Aparición a San Alonso Rodríguez (detalle), Madrid, Real Academia de San Fernando. 
lasco, al rey Jaime I de Aragón y al Dominico Raimundo de Peñafort) consta en los Acta Sanctorum $^{43}$, pero no se menciona la entrega del hábito reproducida por Zurbarán, quien, en cambio, no representa las visiones simultáneas del monarca y del confesor.

Que haya intervenido la Virgen en la fundación de la orden, lo cual han confirmado la Iglesia y los historiadores, ha hecho de la Merced una institución marial por encima de todo. Asimismo, la aparición solamente a Pedro Nolasco, refleja, probablemente, las pretensiones de los Mercedarios en cuanto se refiere al orígen de su orden para que ya no tuviera nada que ver con los Dominicos. En dicha fundación, el papel de San Raimundo ha sido motivo de intensas controversias en el siglo $\mathrm{xx}^{44} \mathrm{y}$, lo más seguro, ya era preocupante para los espíritus en el momento de la canonización. En 1844, González de León menciona un pleito ganado por los Predicadores a los Mercedarios referente a tres cuadros de Zurbarán donde aparecía San Raimundo de Peñafort vestido «de clérigo regular y no con su hábito de Sto. Domingo [...] Los Mercedarios se allanaron, pero para no cumplir la providencia, ocultaron los cuadros y hoy se ignora su paradero ${ }^{45}$. No se han encontrado las minutas del proceso, con lo cual desconocemos su fecha, tal vez más tardía que la ejecución de la serie (lo que explicaría la desaparición de tres cuadros entre 1789 y 1800). De todas formas, esto resulta significativo de la voluntad de los Mercedarios de excluir toda participación de los Domínicos en la fundación de la orden.

El tema de la entrega del hábito por la Virgen, imprescindible para recordar la mediación marial, figuraba, como es lógico, en la serie encargada a Zurbarán. Dos años antes, los Dominicos de San Pablo el Real de Sevilla, también le habían pedido que pintara La Entrega del escapulario domínico al beato Reginaldo de Orleans (Sevilla, Iglesia de la Magdalena). Más adelante, el obrador de Zurbarán volverá a pintar para el convento de San José de la Merced Descalza la Virgen entregando el hábito de la Merced a San Pedro Nolasco (Saint-AmansSoult, colección particular).

Zurbarán, atento a satisfacer perfectamente al comendador Fray Juan de Herrera, se ha atenido con sumo cuidado a las fuentes que se le brindaban. A la derecha, por la ventana cimbrada abierta, se divisa el cielo de un azul muy oscuro, prueba de que se trata de un episodio nocturno. El joven santo, vestido de pardo manto holgado con gruesos pliegues, tiene los rasgos del modelo ya utilizado para representar al santo fundador en la Aparición de San Pedro crucificado a San Pedro Nolasco del Prado (Fig. 15), pintado como aquí adolescente. Nos gustaría imaginar que sirviera de modelo para el pintor su propio sobrino, Sebastián de Zurbarán, que hace profesión en el convento de la Merced de Sevilla en 1630 a los 17 años. Ensimismado, con las manos juntas y el rostro muy puro vuelto hacia la aparición, se parece al San Buenaventura en oración del Museo de Dresde, contemporáneo de este cuadro. Como siempre Zurbarán resulta excelentísimo en sus representaciones de juveniles éxtasis.

Como ocurre en la aparición del Prado, la visión celeste llena toda la parte izquierda del lienzo. La pequeña Virgen coronada, enteramente vestida de blanco, está sentada en una nube clarísima que ilumina la escena. Las nubes en las cuales descansa, así como su nimbo circular pintado en distintos tonos de oro, llevan cabecitas de angelitos pintadas con suma delicadeza. Cuatro grandes angeles músicos acompañan a María. Con largo vestido rosa pálido, el que se encuentra en primer plano, toca un arpa adornado mientras que, a la izquierda de la Virgen, otra criatura celeste, vestida de azul sútil, toca el laúd. Detrás del grupo divisamos la cabeza y el busto envuelto de amarillo de dos cantores. La figura de la Reina de los cielos y la de sus

\footnotetext{
43 Joannes Bollandus, Acta Sanctorum, Tomus primus januarii, Venecia, 1724, p. 408-409.

${ }^{44}$ Yves Dossat, «Les ordres de rachat, les mercédaires», Assistance et Charité, «Cahiers de Fanjeaux», 13, Toulouse, 1978 , p. 365-387.

${ }_{45}$ Felix González de León, Noticia artística, histórica y curiosa [...] de la Ciudad de Sevilla, Sevilla, 1844, p. 370, ed. 1974 , p. 608 .
} 
acompañantes anuncia la de los personajes de la Aparición a San Alonso Rodríguez de 1630 (Madrid, Real Academia de San Fernando) [Fig. 16].

A pesar de la capa de barnices amarillentos, el conjunto del lienzo parece estar en buen estado. Al limpiarlo se tendría que descubrir una firma de la cual aún se puede leer la $« \mathrm{~F} »$ en el centro abajo del cuadro. Por su estructura simplificada hacia lo esencial, por sus refinados colores y la fuerza escultural de la silueta del santo, esta obra maestra resulta característica de la primera manera de Zurbarán.

La muy elevada calidad de los lienzos recien descubiertos de Zurbarán es una prueba mas del nivel alcanzado por el maestro en sus pinturas autógrafas. Naturalmente hay que tener en cuenta este dato a la hora de elaborar el catálogo de la obra del pintor extremeño ${ }^{46}$.

${ }^{46}$ Odile Delenda, catálogo razonado de Francisco de Zurbarán en preparación en el Wildenstein Institute, Paris. 